\title{
BERARSITEKTUR ERA KINI: ANTARA LIVING WITH NATURE DAN LIVING WITHIN NATURE
}

\author{
Lutvi Arnila Meiliyandari ${ }^{1}$, Nabila Khofifah ${ }^{2}$, Asifa Ulima Kafin ${ }^{3}$, Fatimatuz \\ Zahroh $^{4}$, Anas Hidayat ${ }^{5}$ \\ 1-4. Mahasiswa Program Studi Arsitektur, Fakultas Arsitektur dan Desain, \\ Universitas Pembangunan Nasional "Veteran" Jawa Timur \\ Jl. Rungkut Madya No. 1, Surabaya \\ 5. Program Studi Arsitektur, Fakultas Teknik, Universitas Katolik Darma Cendika, \\ J1. Dr. Ir. H. Soekarno No. 201, Surabaya \\ Email: lutviarnila1@gmail.com
}

\begin{abstract}
Abstrak
Arsitektur adalah jawaban dari kebutuhan papan manusia, dari struktur sederhana yang meniru konsep struktur di alam hingga bangunan yang lebih kompleks yang bisa selaras maupun kontras dengan alam sekelilingnya. Alam dan arsitektur merupakan kedua hal yang saling terlepas dan terkait, tarik dan ulur akan eksistensinya. Dua paradigma arsitektur yang masih terasa hingga saat ini; modern dan posmodern, memiliki pandangan yang berbeda atas keduanya. Berdasarkan paradigma itu. arsitek harus memilih posisi dimana dirinya dan ciptaannya berada. Dengan studi kasus bangunan arsitektur di Indonesia, tulisan ini dimaksud untuk menggali cara pandang arsitektur atas alam maupun lingkungan tapak sekaligus juga menuntut arsitek untuk tidak hanya berpihak pada manusia. Menggunaman metode mengumpulkan data dan deskriptif, jurnal ini akan memberikan pandangan paradigma arsitektur manakah yang lebih baik dengan perhatian lebih pada alam dan lingkungan tapak. Meski arsitektur yang disajikan dalam kajian ini sama-sama dibangun di era kontemporer, tetapi memiliki paradigma yang berbeda terhadap alam. Ada yang menggunakan paradigm modern untuk "hidup dengan alam" (living with nature) da nada yang berparadigma postmodern untuk "hidup di dalam alam" (living within nature).
\end{abstract}

Kata kunci: arsitektur, alam, paradigma, modern architecture, post-modern architecture.

\begin{abstract}
Title: Current Architecture: Between Living with Nature and Living within Nature

Architecture is the answer to human needs on shelter, from the basic structure copying the structure concept in nature to more complex buildings that can be in harmony or in contrast with the surroundings. Nature and architecture are two distinct but related things, mutually affecting their existence. The two paradigms of architecture; modern and post-modern, have their own views about them. Based on those paradigms, architect must select the position where they and their creations belong. With the case studies of architecture in Indonesia, this paper aims at exploring architects' points of view about nature and site's coverage and demanding architects not merely to take sides with human being. Using data collection and descriptive method, this paper will provide overview of which architectural paradigm is better with more attention to the nature and the site's coverage. Even though the architectures presented in this study are built in contemporary era, their paradigms about nature are different. Some use the paradigm of living with nature, and others use the paradigm of living within nature.
\end{abstract}

Keywords: architecture, nature, paradigm, modern architecture, post-modern architecture. 


\section{Pendahuluan}

Pada dasarnya arsitektur merupakan jawaban atas permasalahan kebutuhan tempat berlindung bagi manusia. Namun demikian, hubungan antara manusia dan alam, sebagaimana dikonsep oleh manusia, terus berubah seiring waku. Di sepanjang sejarah dan budaya, "alam" telah diteorikan dalam banyak hal: sebagai musuh, kawan, dewa, sumber daya, ilham, teror, atau suaka. Pemikiran tentang arsitektur juga tak luput pada perkembangan tersebut. Perkembangan ini terjadi karena menyesuaikan kebutuhan dan juga kesadaran masyarakat yang kian meluas. Sebut saja pada awal ditemukannya arsitektur, Marc Antoine Laugier (1753) mengatakan "It is the same in architecture as in all other arts: its principles are founded on simple nature, and nature's process clearly indicates its rules". Pernyataan tersebut menjelaskan bahwa penemuan arsitektur didapatkan dari proses meniru prinsip alam karena kebutuhan pada masa itu hanya sebatas untuk tempat tinggal agar bisa bertahan hidup.

Sumalyo (1997) mengatakan bahwa arsitektur Modern mendunia pada awal abad ke-19 ditandai dengan terjadinya revolusi industri dalam bentuk rasionalisasi dan penggunaan mesin secara besar besaran karena metode konstruksi yang digunakan adalah. Prinsip yang digunakan pada era Modern memang sangat berorientasi pada kepentingan ekonomi. Era arsitekur Modern dicap dengan era peduli bagaimana caranya mendapat keuntungan yang besar, dengan cara yang cepat, praktis, dan tidak memakan banyak biaya. Oleh karenanya, prinsip standarisisasi mulai diaplikasikan di mana-mana. Akibatnya, keberagaman di masing-masing tempat di muka bumi mulai terabaikan.
Segala sesuatu yang pada dasarnya berbeda, dipaksa menjadi homogeny (seragam). Berbagai aspek seperti sosiokultur lama kelamaan mulai menghilang. Dalam arsitektur sendiri misalnya, standarisasi arsitektur pada era Modern muncul dan makin tajam dengan adanya "International Style".

Kesadaran masyarakat tentang keberagaman, pentingnya site dan pentingnya mempelajari kondisi lingkungan dalam arsitektur pada hakekatnya merupakan sebuah respon dari ideologi Modern, karena pada era tersebut, arsitektur banyak dibatasi berbagai prinsip dan standar dan memiliki tendensi untuk kurang peduli pada aspek lokalitas di suatu tempat.

Carol dalam buku Introducing Architecture Theory (2012) menjelaskan bahwa sebuah site dari waktu ke waktu akan terus terbentuk dari berbagai aspek yang ada di lingkungannya seperti budaya, politik, ekonomi, iklim, bahkan manusia, dan lain-lain yang kemudian diproyeksikan pada kondisi fisik dan kualitas morfologi site tersebut. Dalam konsep Posmodern, site dan arsitektur tidak dapat dipisahkan dan arsitektur seharusnya dibangun berdasarkan keadaan fisik sebuah site di mana bangunan tersebut berdiri.

Pada era Posmodern, muncul gerakan kontekstual yang mendeklarasikan diri sebagai metode pemulihan lingkungan yang semakin senjang dalam dunia arsitektur dan lingkungnnya, yaitu lingkungan yang semakin putus dengan sejarah atau budaya suatu tempat. Jencks (1990) menyatakan bahwa arsitektur Posmodern adalah arsitektur kontekstual dengan respond to local context dan contextual urbanism. Jencks dalam Alhamdani (2010) juga berpendapat bahwa arsitek Posmodern mengklaim bangunannya berakar pada tempat (place). Dalam rangka 
menciptakan keragaman bahasa arsitektur, arsitektur Posmodern menghargai keunikan lokal setiap tempat (respect to local uniqueness).

Keunikan lokalitas ini meliputi komponen fisik lingkungan dan sosial budaya masyarakatnya, termasuk juga sejarah yang dimilikinya. Kontekstual adalah metode desain yang mempertimbangkan dan memberikan tanggapan terhadap berbagai karakter lingkungannya. Salah satu arsitek di Indonesia yang sangat menjunjung lokalitas adalah Romo Mangun atau Y.B. Mangunwijaya. Di dalam salah satu bukunya Y.B. Mangunwijaya (1992) menulis bahwa manusia bersatu-alam dan ber-satu-hukum dengan dunia semesta fisik di sekelilingnya, tetapi sekaligus juga mengatasi flora, fauna dan alam materi belaka. Dan pada hakekatnya di situlah tugas budaya arsitektural: bagaimana ber-satu-hukum dengan alam semesta, sekaligus mengatasinya: artinya berbudaya, bermakna.

\section{Pembahasan}

Di era saat ini, paradigma Modern dan Posmodern masih banyak digunakan dalam masyarakat dikarenakan masih ada relevansi dengan kebutuhan masyarakat. Oleh karena itu, arsitek memiliki keluasan dan kebebasan dalam memilih paradigma baik yang Modern maupun yang Posmodern. Tetapi sebagai arsitek memilih antara paradigm yang Modern ataupun Posmodern juga ada hubungannya dengan alam. Di sini perlu untuk memilih pendirian dalam nature dan constructed yang biasa diwujudkan dalam bentuk pembangunan pada cleared site atau constructed site. Kedua kasus yang dipaparkan di sini bukan untuk dibandingkan, tetapi untuk disandingkan atau dijajarkan sebagai sebuah pilihan dalam mendesain berkaitan dengan alam.

Berdasarkan timeline keberadaannya maka kasus yang pertama diangkat adalah kasus pada bangunan dengan paradigma arsitektur Modern. Bangunan arsitektur dengan paradigm Modern yang diangkat dalam kajian ini adalah bangunan Studio Tonton milik arsitek Antony Liu, yang pendekatan bentuknya mirip dengan bangunan Ludwig Mies van de Rohe (arsitek dari Bauhaus Jerman, yang kemudian memunculkan International Style di Amerika Serikat). Studio ini terletak di Tangerang dengan luas $850 \mathrm{~m}^{2}$. Pada salah satu seminar, Antony Liu yang mendesain dan memiliki studio ini mengatakan bahwa beliau menginginkan sebuah studio yang intinya hendak memaksimalkan pada view. Dengan tujuan membangun studio yang view-nya bersifat calming, dan didukung tapak yang menyediakan kebutuhan tersebut. Antony Liu memutuskan untuk membuat bangunan full kaca sehingga mendapatkan kesan transparant tanpa sekat dan dapat dikatakan juga bahwa bangunan tersebut terasa seakan menyatu dengan alam. Hal ini sangat mendukung paradigma Modern yang memiliki kesan terbuka serta adanya interaksi antara bangunan dan tapak.

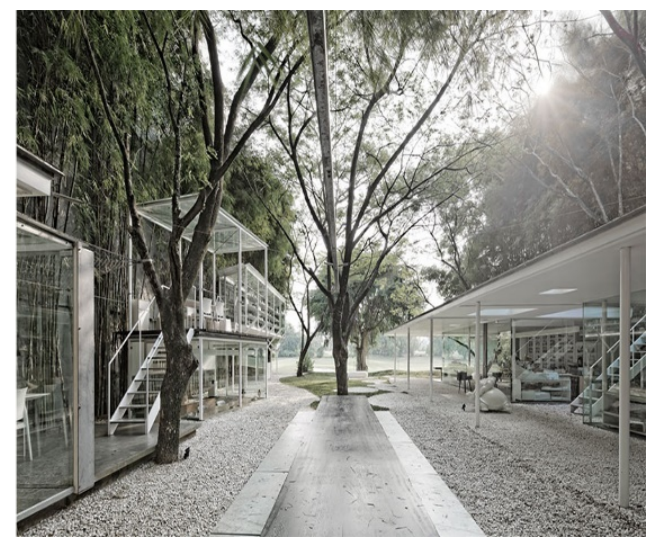

Gambar 1. Bangunan Studio Tonton Sumber: Website Divisare, 2016 
Dengan tujuan awal si arsitek, pendekatan Modern yang ingin living with nature telah terpenuhi. Terbentuk bangunan yang mengedepankan segi fungsionalitas dan ke-efisien-an. Bentuk dasarnya berupa kubus yang dimodifikasi, dalam segi bentuk tidak terlalu banyak yang diubah, hanya saja permainan material di sini sangat menarik dan dapat menimbulkan suasana yang ingin ditimbulkan sang arsitek, dengan pemilihan kaca sebagai material yang mendominasi hampir di seluruh sisi bangunan, ditambah kondisi site yang dikelilingi oleh pepohonan serta lapangan golf, dapat menambahkan keasrian pada bangunan itu sendiri. Tidak ada penambahan ornament-ornamen khusus, menambah penekanan kesan simple pada bangunan ini.

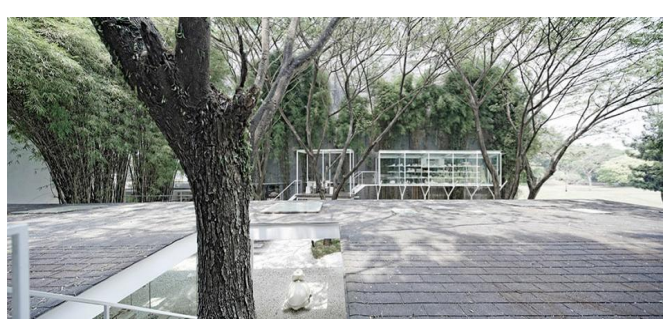

Gambar 2. Bangunan Studio Tonton Sumber: Website Divisare, 2016

Pohon pada tapak juga bukan tanpa alasan dibiarkan tumbuh, hal ini bertujuan sebagai bentuk penghormatan terhadap site tersebut, bahkan ada beberapa pohon juga yang dibiarkan menembus atap bangunan. Selain itu akses sirkulasi pada kendaraan dan manusia juga diberi perkerasan, agar menimbulkan rasa nyaman untuk penghuni dalam menggunakannya.

Pada kasus ini, tapak diumpamakan sebagai sebuah kanvas kosong yang dapat dilukis oleh arsitek sesuai kehendaknya. Mulai dari tapak yang diadakan sesuai keinginan, ketika terbangun juga kembali diperlakukan sesuai dengan keinginan arsitek. Pemilihan material kaca yang hampir di seluruh bangunan juga bermaksud ingin menimbulkan kesan transparant atau merefleksikan keadaan sekitar. Ruang dalam studio ini sangat berhasil menimbulkan suasana nyaman bagi penghuni, ketika mereka melihat kearah dinding, mereka seakan-akan di buat seperti sedang melihat suatu lukisan yang besar. Suasana ini juga semakin terasa sebab atap bangunan yang memiliki ketinggian yang tidak terlalu jauh dari permukaan tanah.

Studio ini merupakan perpaduan dari cleared dan constructed site. Mengapa demikian? Dapat dikatakan cleared sebab sang arsitek menganggap site itu sendiri sebagai kanvas kosong. Sang arsistek melukis site secara keseluruhan dengan menyesuaikan dengan vegetasi yang sudah ada sebelumnya. Pohon menempati posisi sebagaimana mestinya, sehingga terlihat sebagai hiasan dari bangunan itu sendiri. Pemakaian kerikil yang hampir di seluruh lantai bangunan juga menambah daya tarik bangunan tersebut. Di halaman, kerikil juga tidak semerta-merta ditabur begitu saja, namun membentuk suatu pola yang indah. Di samping itu bangunan ini juga tidak dapat dikatakan cleared site, dikarenakan untuk bangunannya itu sendiri lebih mengarah ke constructed dengan pemilihan material kaca, sehingga penghuni dapat melihat view luar dengan jelas, menjadikan setiap dinding bangunan terlihat seperti dikelilingi lukisan besar, dan membuat bangunan seakan-akan berdampingan secara setara dengan alam sekitarnya, living with nature. 
Selanjutnya pada timeline berikutnya, kajian ini mengangkat rumah kediaman arsitek yang lain yang juga terkemuka baik di Indonesia juga di luar Indonesia, yaitu Eko Prawoto dengan studio-nya yang disebut Eko Prawoto Architecture Workshop.

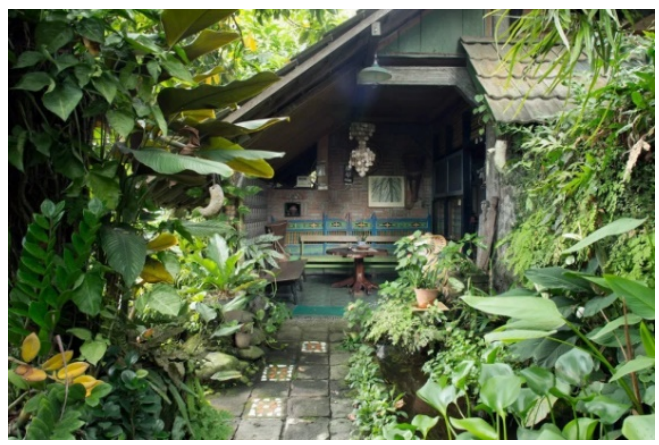

Gambar 3. Rumah kediaman Eko Prawoto di Yogyakarta

Sumber: Website Dekoruma, 2018

Banyak yang mengetahui bahwa Eko Prawoto dalam berarsitektur mengutamakan paradigma bahwa alam juga ikut berkomunikasi dan kita berada di dalamnya. Oleh karenanya, tak heran jika kebanyakan karyanya begitu selaras dengan alam di sekitarnya. Rumah yang menjadi tempat Ia singgah di Yogyakarta merupakan salah satu contoh penerapan prinsip dan pola pikir Eko Prawoto dalam berarsitektur.

Pada rumah biophilic ini, sangat terasa adanya sense of place yang terintegrasi pada alam dalam bangunan. Siapapun yang berada di sana, dapat merasakan adanya suasana ruang yang terbangun dari perpaduan arsitektur dan alam sekitarnya. Ikatan antara arsitektur dan alam yang begitu kuat hingga dapat dirasakan dalam sebuah ruang ini adalah sebuah proyeksi dari pola pikir Eko Prawoto dalam memandang sebuah tapak. Kita hidup di dalam alam (living within nature), sehingga harus mengikuti gerak alam tersebut.
Eko Prawoto tidak hanya menganggap bahwa tapak merupakan sebuah "kanvas kosong" yang bebas diperlakukan sedemkian rupa demi karyanya, namun sebagai suatu entitas besar yang terlebih dahulu terbentuk, dan kita berada di dalamnya. Maka harus dihargai eksistensinya sebagai suatu aspek yang sungguh penting yang tidak dapat dilepas dalam mendesain karya-karyanya.

Cara Eko Prawoto dalam mengeksekusi rancangannya begitu rendah hati dan tidak mengingkari bentuk tapak yang ada. Tak heran jika rumah ini terlihat begitu menyatu dengan alam yang ada di sekitarnya. Salah satu contoh penerapannya adalah guest house yang dibangun di area belakang rumahnya di Dekso, Yogyakarta.

Lahan yang digunakan merupakan lahan berkontur yang ditumbuhi sejumlah vegetasi. Namun, alih-alih meratakan lahan yang berkontur dan menebangi pohon yang sudah terlebih dahulu "berhuni" di sana, Eko Prawoto malah lebih memilih untuk menerima kondisi lahan tersebut apa adanya dan memaksimalkan penggunaan lahan dengan meletakkan sebuah bentuk rumah panggung, dengan beberapa lubang di bagian atap sebagai space untuk tumbuh-kembang pohon.

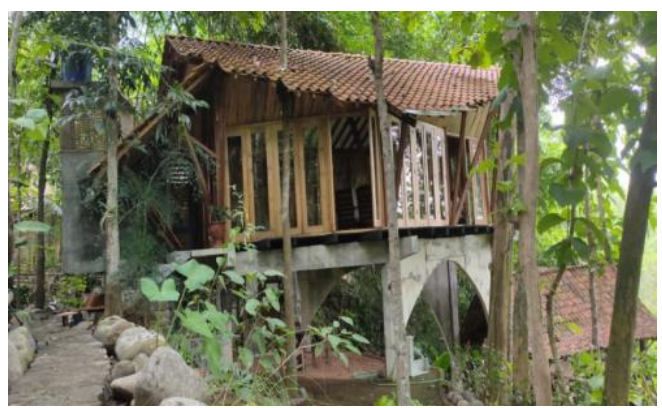

Gambar 4. Guest house Eko Prawoto Sumber: Dokumentasi penulis, 2020. 


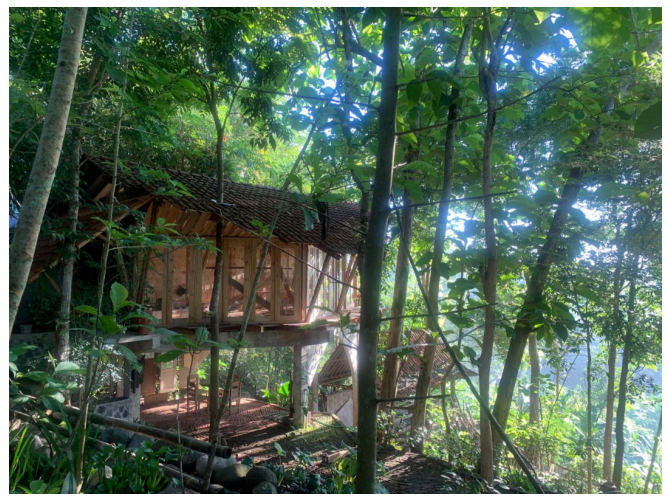

Gambar 5. Guest house Eko Prawoto

Sumber: Dokumentasi Prawoto, 2020.

Contoh lain dari penerapan pola pikir Eko Prawoto terhadap site dalam rumah ini adalah pemilihan materialnya. dalam merancang huniannya, dapat dilihat dengan jelas bahwa material-material yang digunakan merupakan material lokal yang juga sangat bersahabat dengan alam. Jadi, material untuk membangun tempat ini tidak dicari ke tempat yang jauh.

Penggunaan material lokal ini sejalan dengan paradigm Posmodern yang Living Within Nature. Daripada menggunakan material "asing" yang sudah terspesifikasi sesuai fungsi, namun tidak menyatu dengan budaya sekitarnya dan belum tentu dapat bersahabat dengan alam, Eko Prawoto lebih memilih untuk mengeksplor material-material yang tersedia di sekitarnya hingga terciptalah sesuatu yang sederhana namun baru, unik, dan tentunya, menyatu dengan alam serta budaya sekitar.

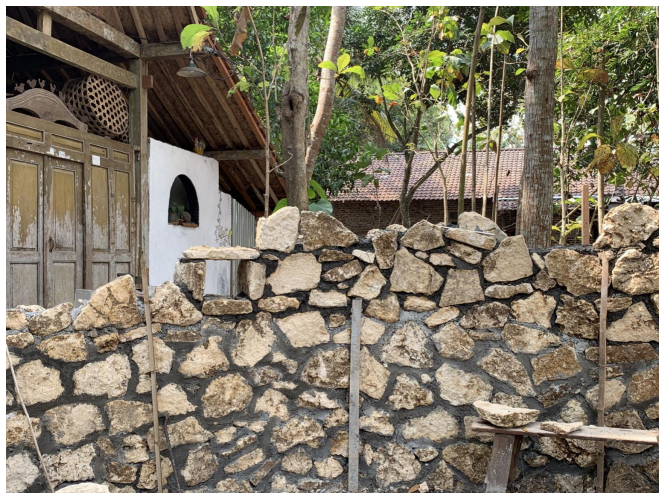

Gambar 6. Batu kapur/ sand stone sebagai material lokal yang digunakan dalam karya Eko Prawoto

Sumber: Dokumentasi Prawoto, 2020.

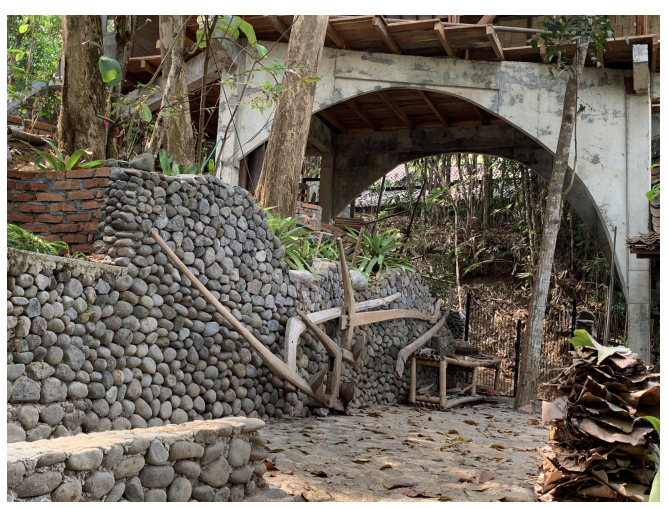

Gambar 7. Batu kali sebagai material lokal yang digunakan dalam karya Eko Prawoto Sumber: Dokumentasi Prawoto, 2020.

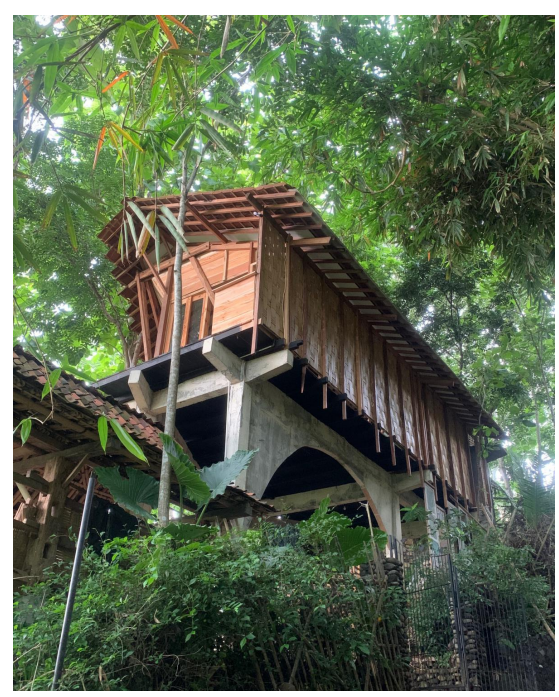

Gambar 8. Kayu dan anyaman bambu sebagai material lokal yang digunakan pada guest house Eko Prawoto Sumber: Dokumentasi Prawoto, 2020. 
Salah satu contoh yang cukup menarik adalah penataan batu bata sebagai perkerasan. Dikarenakan di desa tersedia lebih banyak batu bata dibandingkan paving block, maka Eko Prawoto menyikapi ini dengan mengeksplor penggunaan batu bata tersebut. Daripada menggunakan material yang sulit didapatkan dan terasa "asing" dengan lingkungan sekitarnya, Eko Prawoto justru dengan kreatif berusaha memanfaatkan batu bata itu sebagai material perkerasan. Agar air bisa tetap bisa masuk ke tanah, Beliau menyikapinya dengan solusi yang inovatif, yaitu dengan membuat pola miring-miring. Sehingga, terciptalah win-win solution antara alam dan manusia. Air tetap bisa masuk ke dalam tanah, kemudahan akses terbentuk, dan rancangan yang terbuat tidak terasa "asing" dengan alam dan budaya sekitarnya.

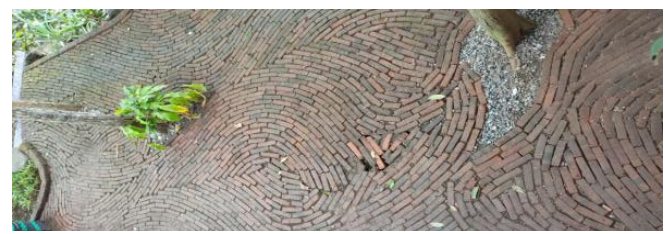

Gambar 9. Tatanan bata pada halaman rumah Eko Prawoto

Sumber: Dokumentasi penulis, 2020.

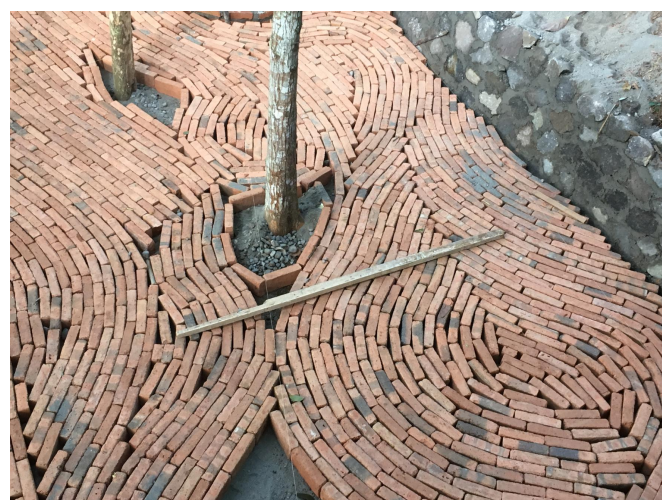

Gambar 10. Tatanan bata pada halaman rumah Eko Prawoto

Sumber: Dokumentasi Prawoto, 2020.

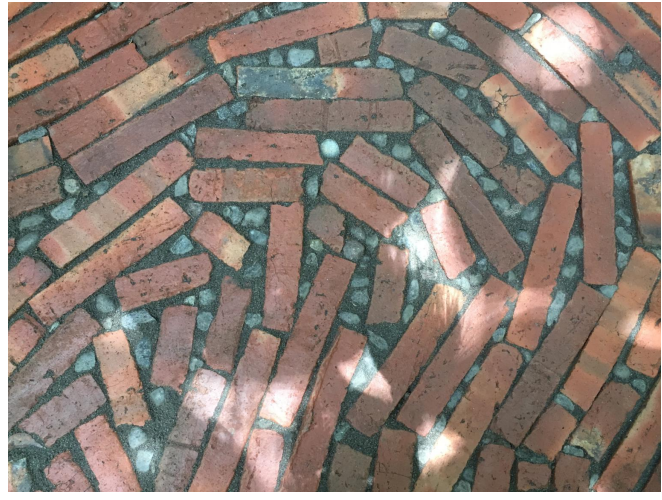

Gambar 11. Detail tatanan bata pada halaman rumah Eko Prawoto

Sumber: Dokumentasi Prawoto, 2020.

Contoh lain dari eksplorasi material lokal yang lekat dengan budaya sekitar dapat terlihat dari ornamen-ornamen yang ada pada rumah ini. Eko Prawoto memunculkan suasana ruang yang kental akan budaya Jawa-Yogyakarta melalui berbagai ornamen yang terdapat di berbagai bagian rumah. Beliau dapat mengeksplor barangbarang tradisional menjadi sesuatu yang baru, yang relevan dengan jaman kini, kemudian ia padukan dengan karyanya. Salah satunya adalah Kerajinan keranjang dari anyaman bambu khas Yogya yang Beliau jadikan sebagai ornamen dinding di sekitar pintu kayu

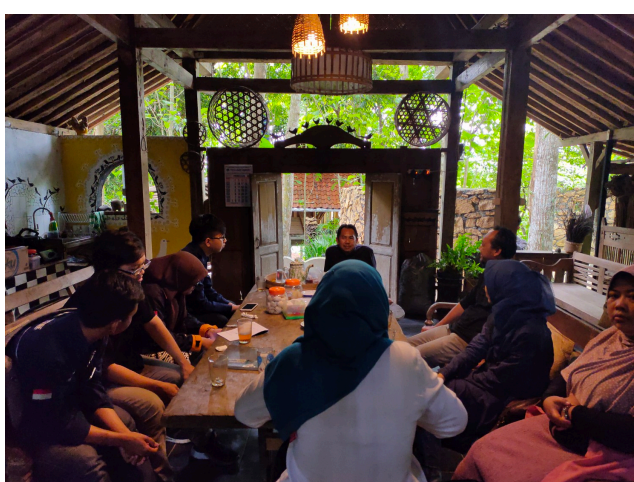

Gambar 12. Suasana di salah satu ruangan di rumah Eko Prawoto

Sumber: Dokumetasi ARCHLAB UPN, 2020.

Jalinan antara hunian Eko Prawoto dengan lingkungan sekitarnya yang dapat dirasakan dalam suasana ruang 
ini merupakan suatu gambaran tentang bagaimana pola pikirnya terhadap site. Pemahamannya mengenai lingkungan sekitar, dan keputusan-keputusan serta solusi kreatif yang dibuat merupakan suatu bukti bahwa Eko Prawoto sangat menghargai tapak, meghormati alam yang melingkupi diri dan rumahnya. Beliau memosisikan kehidupan dan karyanya berada di dalam alam (living within nature),

Eko Prawoto tidak menganggap bahwa alam merupakan sesuatu yang bebas diperdayakan untuk melayani ego karyanya. Kekuatan prinsip dan kreativitas Eko Prawoto inilah yang kemudian dapat menciptakan suatu identitas yang jelas terhadap karyakaryanya yang sangat kental akan prinsip living within nature dari paradigma Posmodern.

\section{Kesimpulan}

Dari pembahasan maka bisa dilihat penjajaran antara arsitektur yang berparadigma Modern yang berkonsep living with nature ataupun yang berparadigma Posmodern yang berkonsep living within nature. Keduanya sama-sama berusaha mengonstruksi dan menanggapi alam di sekitarnya dan bangunannya agar saling selaras. Keduanya memiliki penonjolan fungsi dan guna yang berbeda dan menghasilkan bentuk yang berbeda. Keduanya bisa diterapkan di Indonesia, tetapi tentunya dengan konsekuensi yang berbeda. Arsitektur dengan paradigm Modern mengaggap manusia sebagai pusat (sebagai subjek), sedangkan arsitektur berparadigma Posmodern melihat bahwa justru alam yang menjadi pusat (sebagai subjek). Meski sama-sama menanggapi alam, namun subjeknya berbeda.

$\begin{array}{lcr}\text { Paradigma } & \text { arsitektur } & \text { Modern } \\ \text { didasarkan } & \text { pada logika, } & \text { termasuk }\end{array}$

dalam pandangannya terhadap alam. Juga menyangkut hal-hal yang lain, misalnya bagaimana agar pembiayaan konstruksi tidak terlalu mahal dan proses pembangunan yang lebih cepat dan efisien berdasarkan kebutuhan. Ini sangat terlihat pada Studio Tonton.

Arsitektur dengan paradigm Posmodern seperti rumah Eko Prawoto lebih mengedepankan keseimbangan antara logika dan "rasa", pertimbangannya bukan hanya kebutuhan, tetapi juga "marwah" arsitektur yang berani "membuat sendiri" (sebagai upaya mengurangi ketergantungan pada material industrial) dengan rasa estetika yang berbeda, tapi orisinil.

Di samping itu, masing-masing paradigma juga memiliki kelebihan dan kekurangannya sendiri. Yang perlu di perhatikan adalah perlakuan pada lahan, yang mana harus diperlakukan secara bertanggung jawab. Arsitek harus menyadari konsekuensi logis dari apa yang dibuatnya.

Jadi, para arsitek seyogyanya memperhatikan hal ini dan memperlakukan alam dan site dengan lebih bijak. Pada banyak kasus, arsitek lebih banyak menjadi subjek yang dominan, tanpa melakukan "dialog" dengan site. Mestinya, arsitek perlu menyeimbangkan logika dan rasa, agar bisa menangkap dengan baik apa yang "dikatakan" oleh site, oleh lingkungan, oleh alam.

\section{Daftar Pustaka}

Sumalyo, Yulianto. (2005). Arsitektur Modern: Akhir abad XIX dan abad $X X$. Edisi ke 2. Yogyakarta: Gadjah Mada University Press.

Alhamdani, M. R. (2010). Strategi dan aplikasi pendekatan kontekstual dalam perancangan karya arsitektural Renzo Piano (Tesis 
Program Pasca Sarjana,

Universitas Gadjah Mada, 2010.

Tidak dipublikasikan).

Jencks, Charles. (1980). Late-Modern architecture and other essays. London: Academy Editions Ltd.

Mangunwijaya, Y. B. (1992). Wastu citra: Pengantar ke ilmu budaya bentuk arsitektur. Jakarta:

Gramedia Pustaka Utama. 